\title{
VISUALISASI SISTEM ASYMMETRIC DIGITAL SUBSCRIBER LINE (ADSL) DENGAN MENGGUNAKAN MODULASI QUADRATURE PHASE SHIFT KEYING (QPSK)
}

\author{
Ahmat Sobri ${ }^{1}$, Irwan Dinata ${ }^{2}$, Rudy Kurniawan ${ }^{3}$ \\ 1,2,3 Jurusan Teknik Elektro Universitas Bangka Belitung \\ e-mail: babel_milano@yahoo.com,rudy14k@gmail.com
}

\begin{abstract}
Asymmetric Digital Subscriber Line (ADSL) system is an access technology that enables communication of data, voice and video simultaneously on copper access media. Data communication can not be avoided from the noise, not least ADSL systems are experiencing an error in delivery caused by the noise that makes the value of the bit error rate (BER) increase. Therefore, we need a way to reduce the noise so as to minimize the value of BER. To reduce noise and obtain the required value BER modulation method Quadrature Phase Shift Keying (QPSK) in ADSL systems. Visualization system is needed to determine the performance of the ADSL system and knowing that caused the BER. From the results of visualization by providing 64 bits of data input, constellation display have spread the data but does not distort the shape of constellation. When constellation entrance to the Additive White Gaussian Noise (AWGN) channel with a deviation between $0 \mathrm{~dB}-20 \mathrm{~dB}$ and intervals of $2 \mathrm{~dB}$, resulting BER value 0.3906 when the Signal to Noise Ratio (SNR) is $0 \mathrm{~dB}$ until BER is zero when the SNR range between $9 \mathrm{~dB}-20 \mathrm{~dB}$.
\end{abstract}

Keywords: ADSL, AWGN, BER, QPSK, SNR

INTISARI

Sistem Asymmetric Digital Subscriber Line (ADSL) merupakan teknologi akses yang memungkinkan terjadinya komunikasi data, suara dan video secara bersamaan pada media akses tembaga. Komunikasi data tidak dapat dihindarkan dari adanya derau, tidak terkecuali sistem ADSL yang mengalami kesalahan dalam hal pengiriman yang disebabkan adanya derau sehingga membuat nilai bit error rate (BER) meningkat. Oleh karena itu, diperlukan cara untuk mengurangi derau sehingga dapat memperkecil nilai BER. Untuk mengurangi derau dan mendapatkan nilai BER maka diperlukan metode modulasi Quadrature phase shift keying (QPSK) pada sistem ADSL. Visualisasi sistem dibutuhkan untuk mengetahui kinerja dari sistem ADSL dan mengetahui BER yang di timbulkan. Dari hasil visualisasi dengan memberikan masukan data 64 bit, menampilkan konstelasi yang mengalami penyebaran data tetapi tidak merusak bentuk dari konstelasi. Ketika konstelasi masuk ke kanal Additif White Gaussian Noise (AWGN) dengan simpangan antara $0 \mathrm{~dB}-20 \mathrm{~dB}$ dan interval $2 \mathrm{~dB}$, dihasilkan nilai BER 0.3906 pada saat Signal to Noise Ratio (SNR) bernilai $0 \mathrm{~dB}$ sampai akhirnya BER bernilai nol pada saat SNR berkisar antara $9 \mathrm{~dB}-20 \mathrm{~dB}$.

Kata Kunci : ADSL, AWGN, BER, QPSK, SNR

\section{PENDAHULUAN}

Komunikasi merupakan cara untuk menyampikan informasi kepada seseorang atau klayak ramai dengan cara berkomunikasi secara langsung, dengan telepon ataupun dengan jaringan internet. Perkembangan teknologi jaringan internet yang sangat pesat pada saat ini banyak sekali masyarakat yang sudah berkomunikasi dengan menggunakan jaringan internet ditambah lagi dengan kecepatan internet yang sangat meningkat. Tetapi untuk menikmati jaringan internet yang cepat diperlukan biaya yang cukup besar. Cara lain untuk bisa berkomunikasi lewat jaringan internet dengan biaya yang murah adalah menggunakan jaringan internet yang sudah terpasang seperti jaringan telepon yang menggunakan saluran sepasang kawat tembaga Public Service Telephone Network (PSTN). Dengan perkembangan teknologi jaringan internet, PSTN dapat dioptimalkan untuk penggunaan transmisi data digital kecepatan tinggi. Teknologi ini sering disebut dengan Asymmetric Digital Subscriber Line (ADSL). ADSL merupakan teknologi akses yang memungkinkan terjadinya komunikasi data, suara dan video secara bersamaan pada media akses tembaga. Komunikasi data tidak dapat dihindarkan dari adanya derau, tak terkecuali 
sistem ADSL yang mengalami kesalahan dalam hal pengiriman disebabkan adanya derau sehingga membuat nilai bit error rate (BER) meningkat. Untuk itu diperlukan cara untuk mengurangi derau yang secara otomatis memperkecil nilai BER. Untuk mengurangi derau dan mendapatkan nilai BER yang kecil maka diperlukan metode modulasi Quadrature phase shift keying (QPSK) pada sistem ADSL. Suatu visualisasi sistem perlu dibangun untuk dapat mengetahui kinerja dari sistem ADSL dan mengetahui nilai BER yang ditimbulkan.

\section{TEORIDASAR}

\section{A. ADSL}

Mekanisme kerja sistem ADSL dapat dilihat dalam Gambar 1.

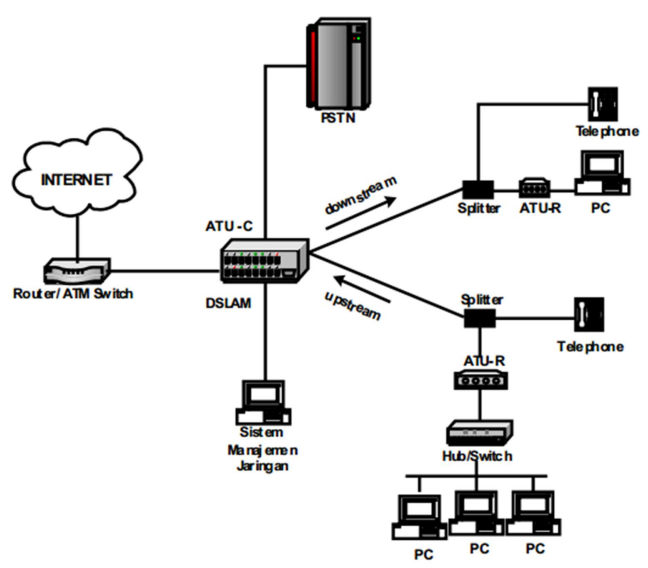

Gambar 1. Mekanisme kerja sistem ADSL (Sumber : Gathut Nugroho)

Mekanisme kerja ADSL menurut Gambar 1 dapat dijelaskan sebagai berikut : informasi dari internet dapat diakses setelah melalui router/ATM switch diteruskan ke DSLAM (Digital Subscriber Line Access Multiplexer). Di dalam DSLAM sendiri terdapat dua saluran yaitu suara dan data, sehingga perlu adanya sistem manajemen jaringan untuk mengaturnya. Dari DSLAM informasi diteruskan ke sisi pelanggan masuk ke splitter. Di dalam splitter input DSLAM dipisah menjadi dua yaitu berupa voice dan data. Untuk suara langsung menuju saluran telepon sedangkan data menuju modem ADSL/ATU-R sehingga tidak terjadi interferensi antara sinyal suara dan data. Modem ADSL siap digunakan untuk koneksi internet, tetapi jika ingin dishare maka perlu adanya hub/switch untuk membagi koneksi dengan yang lain.

\section{B. Hubungan $E_{b} / N_{o}$ dengan $S N R$}

Keunggulan $E_{b} / N_{o}$ dibandingkan SNR adalah kuantitas yang bergantung kepada bandwidth. Dapat dihubungkan $E_{b} / N_{o}$ dengan SNR seperti berikut:

$$
\frac{E_{b}}{N_{o}}=\frac{S}{N_{o} R}
$$

Parameter $N_{o}$ adalah kepadatan daya derau dalam Watt/Hertz. Maka, derau dalam sinyal dengan bandwidth $B_{T}$ adalah seperti berikut :

$$
N=N_{o} B_{T}
$$

dengan $B_{T}$ bernilai 1

Dengan substitusi persamaan (2) ke dalam persamaan (1), diperoleh :

$$
\begin{aligned}
& N_{o}=\frac{N}{B_{T}} \rightarrow \frac{E_{b}}{N_{o}}=\frac{S}{\frac{N}{B_{T}} * R} \\
& \frac{E_{b}}{N_{o}}=\frac{S}{N} \frac{B_{T}}{R} \\
& \frac{S}{N}=\frac{E_{b}}{N_{o}} \frac{R}{B_{T}} \\
& \frac{S}{N}=\frac{E_{b} * R}{N_{o}} \\
& S N R=\frac{E_{b} * R}{N_{o}}
\end{aligned}
$$

\section{Modulasi}

Modulasi digital digunakan untuk merepresentasikan bit - bit atau simbol - simbol dalam bentuk sinyal analog supaya dapat ditransmisikan. Modulasi digital dapat berupa Phase Shift Keying (PSK), Frequency Shift Keying (FSK), Amplitude Shift Keying (ASK), dan Quadrature Amplitude Shift Keying (QAM). Modulasi ASK, FSK, dan PSK dapat dilihat pada Gambar 2.

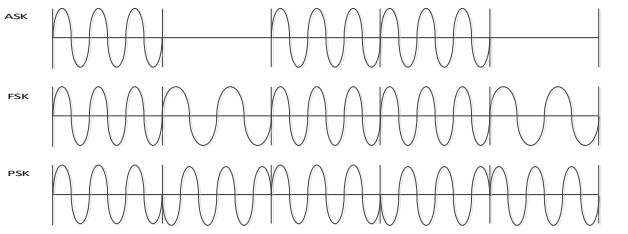

Gambar 2. Modulasi ASK, FSK, dan PSK (Sumber : Filbert \& Dadang, 2010)

Jika pada binery phase shift keying (BPSK) hanya dikirimkan sinyal pada sumbu real saja maka pada QPSK dikirimkan sinyal pada 
sumbu real (sumbu I) dan sumbu imajiner (sumbu Q). Oleh karena itu konstelasinya adalah $\{a(1+j), a(1-j), a(-1+j), a(-1-$ $j)\}$. Untuk yang paling standar kita berikan $a=$ 1. Konstelasi QPSK terlihat seperti pada Gambar 3.

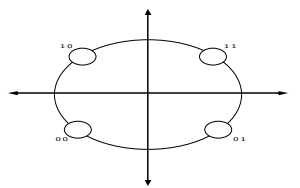

Gambar 3. Konstelasi QPSK (Sumber : Filbert Dadang, 2010)

\section{METODE PENELITIAN}

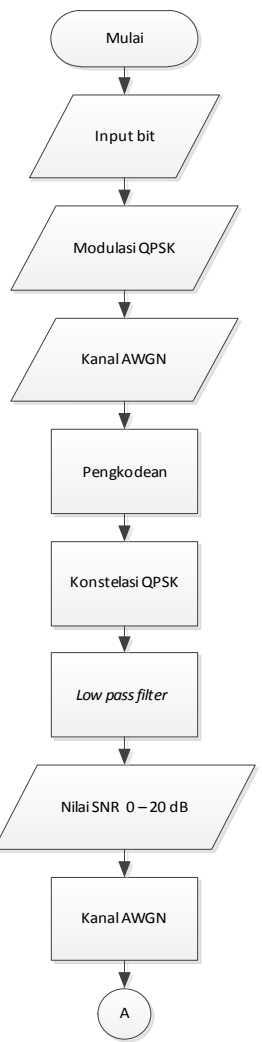

Gambar 4. Diagram Alir Perancangan Simulasi

\section{HASIL DAN PEMBAHASAN}

\section{A. Hasil Proses Visualisasi Pengolahan Data} pada Transmitter

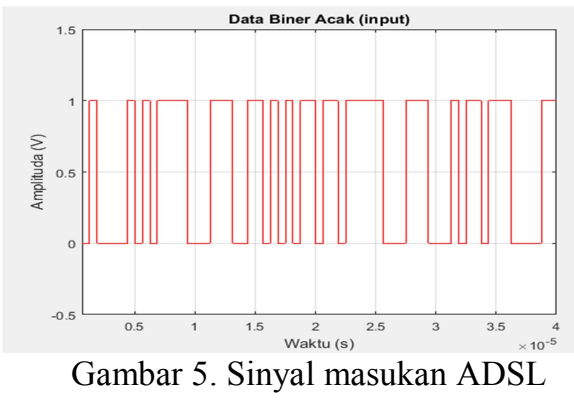

Pada Gambar 5 hanya menampilkan sinyal keluaran sebanyak 64 bit dengan interval waktu (Tb) yang dibutuhkan untuk membangkitkan satu bit sinyal informasi adalah 6,25 x 10-7 detik atau dengan kata lain mempunyai laju data $\mathrm{R}=1,6$ Mbps. Masukan dengan jumlah sinyal informasi 64 bit dengan periode waktu yang dibutuhkan untuk membangkitkan seluruh bit sinyal masukan adalah $=6,25 \times 10-7 \times 64$ bit $=$ 4x10-5 detik.

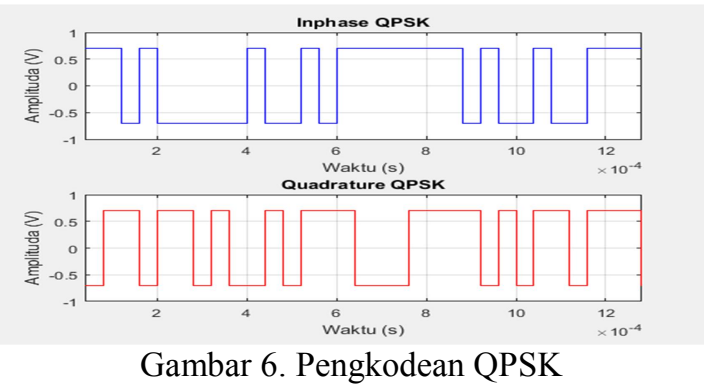

Pada Gambar 6 merupakan sinyal pengkodean QPSK. Sinyal pengkodeaan ini diperoleh dengan berubah data biner menjadi data modulator dan kemudian data modulator dipisahkan antara data inphase dan quadrature.

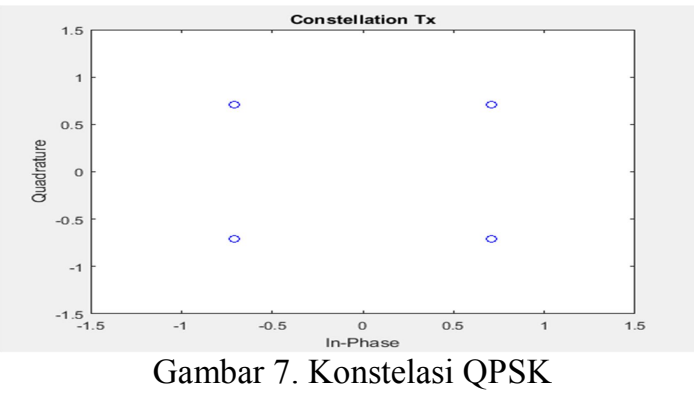

Gambar 7 menjelaskan tentang konstelasi modulasi QPSK yang menggabungkan 2 bit menjadi satu simbol dan menghasilkan 4 kondisi yang berbeda.

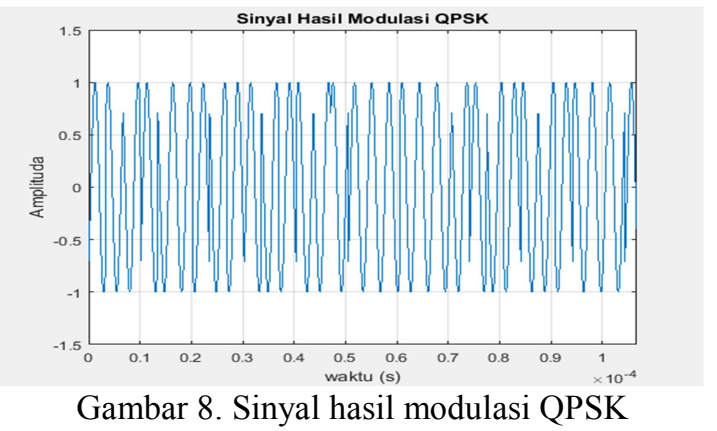

Pada Gambar 8 yaitu sinyal keluaran dari modulasi QPSK yang di dapatkan dari data pengkodean (simbol) yang diubah menjadi data desimal kemudian data tersebut dibagi dengan $\pi$ 
x 1800. Dan terbentuklah gambar dari modulasi QPSK yang berbentuk gelombang sinus.

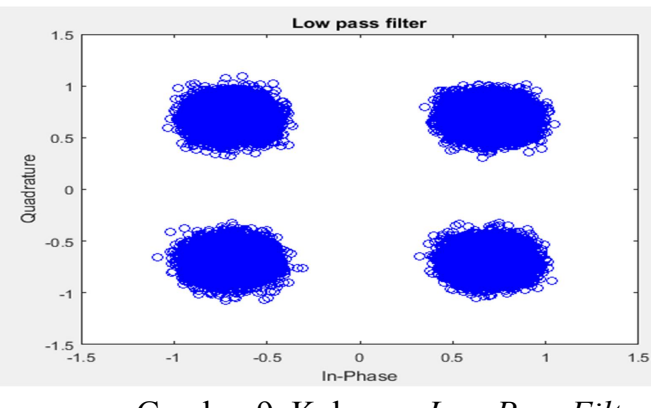

Low pass filter membatasi keluaran dari konstelasi QPSK dengan spektrum frekuensi carrier $790 \mathrm{kHz}$. Sehingga hanya menampilkan konstelasi yang berada dibawah frekuensi cut off $790 \mathrm{kHz}$.

\section{B. Hasil proses visualisasi saluran transmisi Channel AWGN}

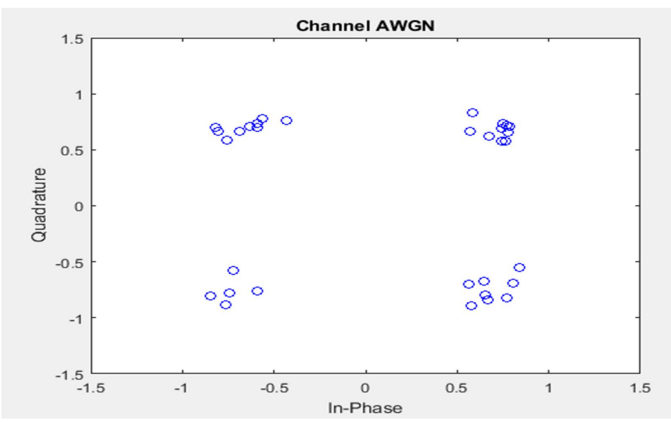

Gambar 10. Keluaran Channel AWGN Masukan 64 Data Bit

Pada Gambar 10 ini sinyal keluaran LPF mengalami penambahan derau putih gaussian dengan nilai simpangan yang dapat diganti mulai dari nilai simpangan AWGN sebesar $2 \mathrm{~dB}$, dan nilai SNR mulai dari $0 \mathrm{~dB}-20 \mathrm{~dB}$.

Tabel 1. BER terhadap SNR 64 bit

\begin{tabular}{cc}
\hline SNR & BER \\
\hline 0 & 0.3906 \\
2 & 0.1875 \\
4 & 0.0625 \\
6 & 0.0313 \\
8 & 0.0156 \\
$9 \quad-20$ & 0 \\
\hline
\end{tabular}

Tabel 1 menunjukkan kondisi BER terhadap SNR pada simulasi ADSL. Nilai BER terhadap SNR yang ditujukkan merupakan nilai pada masukan data 64 bit. Semakin besar nilai dari SNR maka nilai BER akan semakin kecil, ini menunjukan error semakin kecil.
C. Hasil Proses Visualisasi pada Receiver

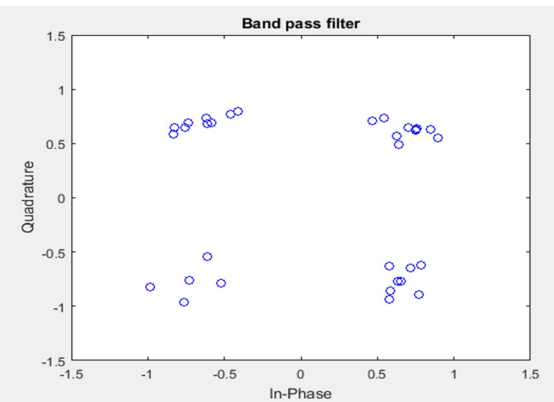

Gambar 11. Keluaran Band Pass Filter

Filter Bandpass membatasi sinyal keluaran kanal AWGN pada frekuensi cutoff bawah 10 $\mathrm{kHz}$ dan pada frekuensi cutoff atas $790 \mathrm{kHz}$ sehingga yang ditampilkan hanya sinyal informasi yang berada diantara dua frekuensi cutoff tersebut. Sinyal informasi hasil pemfilteran ini menghasilkan sinyal konstelasi yang berbeda akibat adanya pemodelan kanal AWGN karena saat proses pemfilteran sinyalsinyal informasi yang banyak mengandung derau akan dihilangkan.

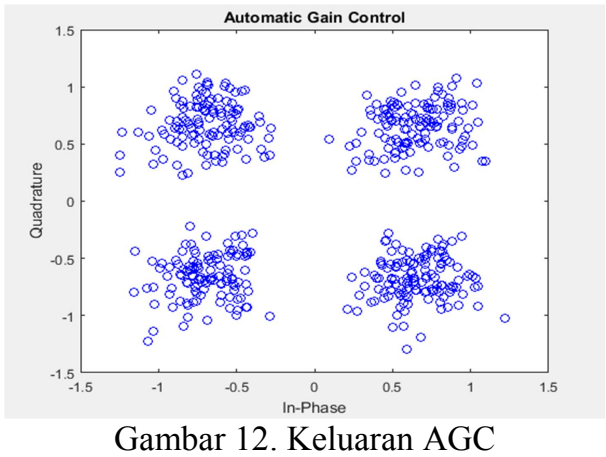

Automatic Gain Control (AGC) digunakan untuk menguatkan kembali konstelasi dari band pass filter agar didapat konstelasi yang diinginkan. Tetapi dilihat dari bentuk gambar bahwa konstelasi band pass filter hampir sama dengan konstelasi automatic gain control.

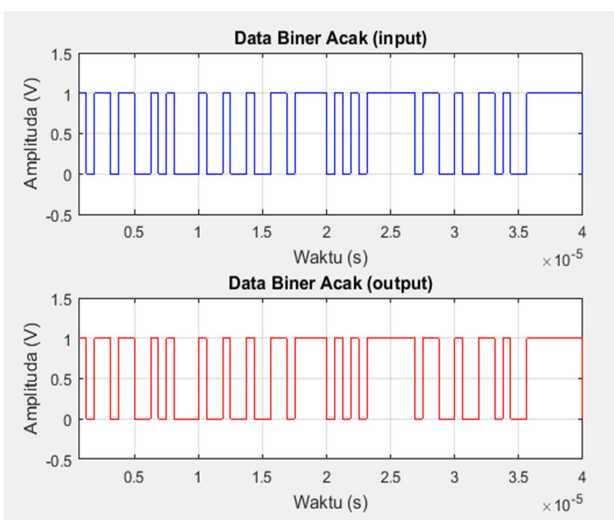

Gambar 13. Hasil Data Masukan dan Keluaran 
Gambar 13 menujukan data masukan 64 bit dengan data input sama dengan data output. Jadi data yang dikirim dari awal di pengkodean dan kemudian dikonstelasikan, difilter dengan low pass filter dan masuk ke kanal AWGN yang memiliki noise dan kemudian di filter dengan band pass filter dan dikuatkan dengan menggunakan automatic gain control dan terakhir didemodelatorkan. Dan data yang dikirim tersampaikan dengan baik tanpa ada perubahan dengan data lain yaitu terkirim dengan baik ke pelanggan.

\section{Hasil Visualisasi Grafik SNR Terhadap BER ADSL}

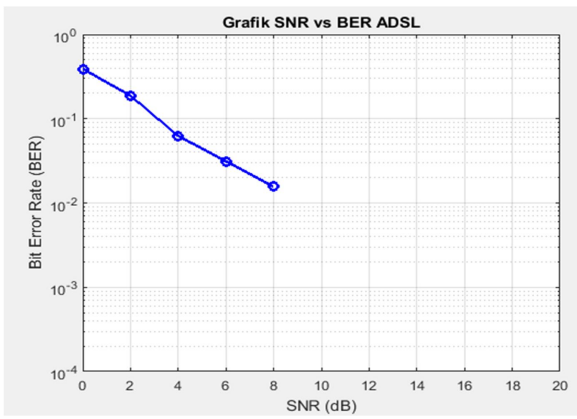

Gambar 14. Grafik SNR terhadap BER ADSL Masukan 64 bit

Hasil pengujian BER yang ditunjukkan pada Gambar 14 dilakukan dengan masukan data 64 bit yang dibangkitkan secara acak. Sinyal BER yang dihasilkan tersebut terlihat dari SNR yang diberikan sebanyak $0 \mathrm{~dB}$ sampai 20dB. Pada Gambar 14, terlihat grafik berhenti pada rentang SNR $8 \mathrm{~dB}$ dengan nilai BER 0.0156 sampai SNR $20 \mathrm{~dB}$ dengan nilai nol.

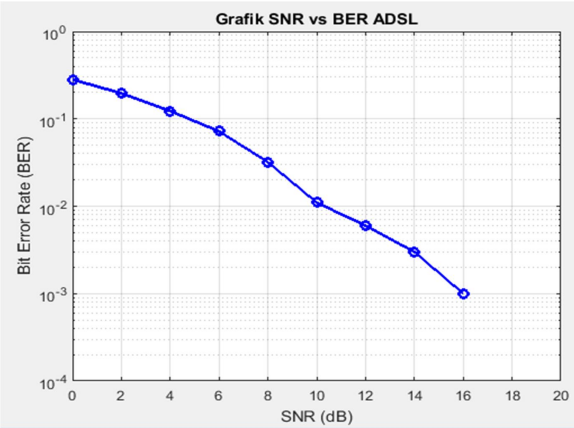

Gambar 15. Grafik SNR Terhadap BER ADSL Masukan 1000 bit

Hasil pengujian BER yang ditunjukkan pada Gambar 15 dilakukan dengan masukan data 1000 bit yang dibangkitkan secara acak. Sinyal BER yang dihasilkan tersebut terlihat dari SNR yang diberikan sebanyak $0 \mathrm{~dB}$ sampai 20dB. Pada Gambar 15, terlihat grafik berhenti pada rentang SNR $16 \mathrm{~dB}$ dengan nilai BER 0.0010 sampai SNR $20 \mathrm{~dB}$ dengan nilai nol.

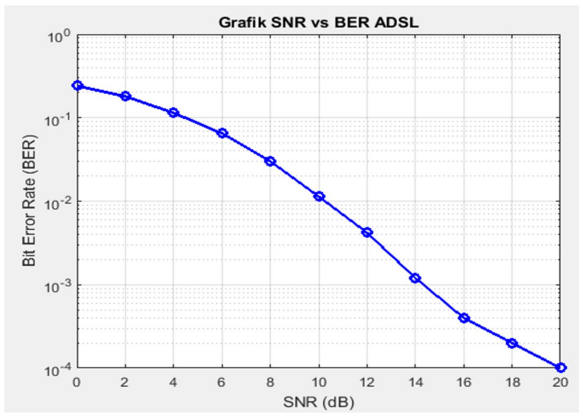

Gambar 16. Grafik SNR Terhadap BER ADSL Masukan 10000 bit

Hasil pengujian BER yang ditunjukkan pada Gambar 16 dilakukan dengan masukan data 10000 bit yang dibangkitkan secara acak. Sinyal BER yang dihasilkan tersebut terlihat dari SNR yang diberikan sebanyak $0 \mathrm{~dB}$ sampai 20dB. Pada Gambar 16, terlihat grafik berhenti pada rentang SNR $20 \mathrm{~dB}$ dengan nilai BER 0.0156 sampai SNR $20 \mathrm{~dB}$ dengan nilai 0.0001 .

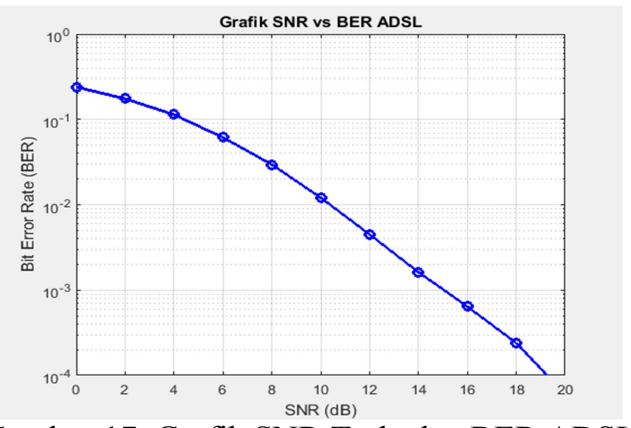

Gambar 17. Grafik SNR Terhadap BER ADSL Masukan 50000 bit

Hasil pengujian BER yang ditunjukkan pada Gambar 17 dilakukan dengan masukan data 50000 bit yang dibangkitkan secara acak. Sinyal BER yang dihasilkan tersebut terlihat dari SNR yang diberikan sebanyak $0 \mathrm{~dB}$ sampai 20dB. Pada Gambar 17, terlihat grafik berhenti pada rentang di bawah SNR $20 \mathrm{~dB}$ dengan nilai BER 0.0001.

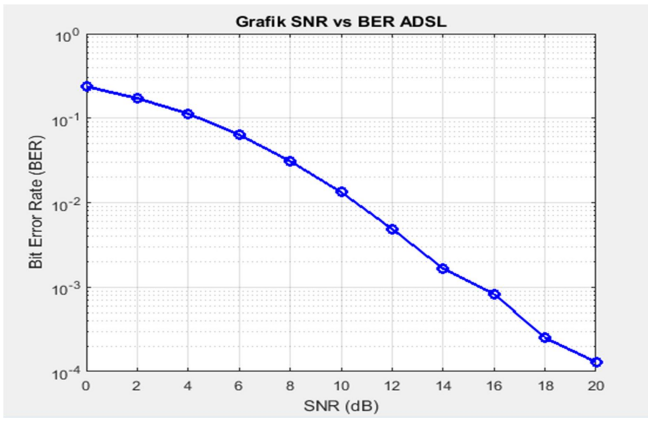

Gambar 18. Grafik SNR Terhadap BER ADSL Masukan 100000 bit 
Hasil pengujian BER yang ditunjukkan pada Gambar 18 dilakukan dengan masukan data 100000 bit yang dibangkitkan secara acak. Sinyal BER yang dihasilkan tersebut terlihat dari SNR yang diberikan sebanyak $0 \mathrm{~dB}$ sampai 20dB. Pada gambar 4.18, terlihat grafik berhenti pada rentang di bawah SNR $20 \mathrm{~dB}$ dengan nilai BER 0.0001 .

\section{KESIMPULAN}

Dari hasil visualisasi sistem ADSL yang dilakukan dengan teknik modulasi QPSK pada Kanal AWGN dapat ditarik beberapa kesimpulan sebagai berikut:

1. Pada transmitter, dari masukan data 64 sampai dengan 100000 bit konstelasi mengalami penyebaran data ketika masuk low pass filter tetapi tidak merusak bentuk dari konstelasi.

2. Kanal AWGN diberi nilai simpangan 0 $\mathrm{dB}-20 \mathrm{~dB}$ dengan interval $2 \mathrm{~dB}$, menghasilkan nilai BER 0.3906 pada SNR 0 dB sampai akhirnya nilai BER 0 pada SNR 9-20 dB pada masukan data 64 bit.

3. Pada receiver, data mengalami derau ketika melewati kanal AWGN, dan difilter dengan BPF dan AGC kemudian diperbaiki demodulator sehingga menghasilkan data yang sama dengan input.

4. Nilai BER paling besar terdapat pada masukan 64 bit, yaitu 0.3906 dan terkecil pada masukan 100000 bit data, yaitu 0.2367 .

\section{DAFTAR PUSTAKA}

[1] Aditya, dkk. (2010). Visualisasi Modulasi 16-QAM Pada Kanal AWGN. Institut Teknologi Sepuluh Nopember (ITS), Surabaya.

[2] Budi P, Arjuni. (2011). Modul Dasar Sistem Telekomunikasi. Jurusan Pendidikan Teknik Elektro, Universitas Pendidikan Indonesia.

[3] Indriaswari, Tri Yosiana. (2011). Visualisasi Sistem ADSL (Asymmetric Digital Subscriber Line) Dengan Menggunakan Modulasi QAM (Quadrature Amplitude Modulation), Universitas Diponegoro Semarang.
[4] Juwono, Filbert Hilman, dan Dadang Gunawan. (2010). Prinsip-Prinsip OFDM. Penerbit ANDI, Yogyakarta.

[5] Kusuma Wijaya, Sastra. (2010). Diktat Elektronika I, Fisika FMIPA, Universitas Indonesia.

[6] Nugroho., Purwanto. (2011). Simulasi Modulasi Discrete Multitone pada Asymmetric Digital Subscriber Line. Universitas Diponegoro Semarang.

[7] Pamungkas, Wahyu dkk. (2012). Modulasi Digital Menggunakan Matlab. Akademi Teknik Telekomunikasi Sandhy Putra Purwokerto, Purwokerto.

[8] Pradana, Adhi. (2008). Analisis Kinerja Discrete Multitone (DMT) Pada Teknologi Asymmetric Suscriber Digital Line (ADSL). Teknik Elektro, Fakultas Teknik, Universitas Sumatera Utara, Medan.

[9] Susilawati., Indah, 2009, Teknik Telekomunikasi Dasar-Kuliah 2 Derau, Program Studi Teknik Elektro, Fakultas Teknik Dan Ilmu Komputer, Universitas Mercu Buana Yogyakarta.

[10] The Mathworks, Inc. (2015). Communications System. ToolboxTM User's Guide.

[11] Ugahari, Rangga. (2009). Perancangan Automatic Gain Kontrol Untuk Mobile Wimax pada Frekuensi 2,3 Ghz. Universitas Indonesia. 